\title{
Comparing tide gauge observations to regional patterns of sea-level change (1961-2003)
}

\author{
A. B. A. Slangen ${ }^{1, *}$, R. S. W. van de Wal ${ }^{1}$, Y. Wada ${ }^{2}$, and L. L. A. Vermeersen ${ }^{3,4}$ \\ ${ }^{1}$ Institute for Marine and Atmospheric research Utrecht (IMAU), Utrecht University, Princetonplein 5, \\ 3584 CC Utrecht, the Netherlands \\ ${ }^{2}$ Department of Physical Geography, Utrecht University, Heidelberglaan 2, 3584 CS Utrecht, the Netherlands \\ ${ }^{3}$ Delft Climate Institute, Faculty of Aerospace Engineering, TU Delft, Kluyverweg 1, 2629 HS Delft, the Netherlands \\ ${ }^{4}$ Royal Netherlands Institute for Sea Research (NIOZ), Landsdiep 4, 1797 SZ 't Horntje, the Netherlands \\ *now at: CSIRO Oceans and Atmosphere flagship, Castray Esplanade, Hobart, TAS 7001, Australia
}

Correspondence to: A. B. A. Slangen (aimee.slangen@gmail.com)

Received: 26 February 2014 - Published in Earth Syst. Dynam. Discuss.: 6 March 2014

Revised: 21 May 2014 - Accepted: 21 May 2014 - Published: 26 June 2014

\begin{abstract}
Although the global mean sea-level budget for the 20th century can now be closed, the understanding of sealevel change on a regional scale is still limited. In this study we compare observations from tide gauges to regional patterns from various contributions to sea-level change to see how much of the regional measurements can be explained. Processes that are included are land ice mass changes and terrestrial storage changes with associated gravitational, rotational and deformational effects, steric/dynamic changes, atmospheric pressure loading and glacial isostatic adjustment (GIA). The study focuses on the mean linear trend of regional sea-level rise between 1961 and 2003. It is found that on a regional level the explained variance of the observed trend is 0.87 with a regression coefficient of 1.07. The observations and models overlap within the $1 \sigma$ uncertainty range in all regions. The main processes explaining the variability in the observations appear to be the steric/dynamic component and the GIA. Local observations prove to be more difficult to explain because they show larger spatial variations, and therefore require more information on small-scale processes.
\end{abstract}

\section{Introduction}

Rising sea levels may have serious impacts on coastal communities in the near future (Nicholls and Cazenave, 2010), and thus sea-level change is a central topic in climate change.
It is therefore important to understand sea-level change and the processes that contribute to it.

Despite the fact that the past global mean sea-level budget can now be closed (e.g. Church et al., 2011; Gregory et al., 2012), the understanding of sea-level changes on a regional scale is still limited. Church et al. (2004) used tide gauge measurements in combination with satellite information to estimate past regional distributions of sea-level change, and regional variations observed by satellites could be reproduced with ocean circulation models (e.g. Wunsch et al., 2007; Lombard et al., 2009), but these methods do not allow for the identification of individual processes contributing on regional scales. In order to estimate the magnitude of various contributing processes to regional sea-level change, Plag (2006) scaled fingerprints of secular trends in steric changes, ice sheets, and GIA to match tide gauge records, which led to an explained variance of $15 \%$. However, Plag (2006) could not yet include important contributions to sea-level change, such as glacier melt and changes in terrestrial water storage.

In this study, we will examine more processes causing regional variations in sea-level change than before. Specific processes that are included are land ice mass changes (e.g. Dyurgerov and Meier, 2005; Rignot et al., 2011), steric changes through temperature and salinity variations (Levitus et al., 2012), and glacial isostatic adjustment [GIA] (Peltier, 2004). In addition, changes in terrestrial storage such as groundwater extraction (Wada et al., 2012) and water impoundment behind dams (Chao et al., 2008), as well as 
changes in atmospheric pressure loading (AL) are included (Ross, 1854; Wunsch and Stammer, 1997).

The observations used in this study are tide gauge (TG) observations, as provided by the Permanent Service for Mean Sea Level (PSMSL, Holgate et al. (2013)). TGs are devices attached to the earth's surface which measure local variations in relative sea level. They have a sparse spatial coverage but provide long data series compared to satellites. A process that is not included in this study is vertical land movement from subsidence or tectonics. These changes can be measured by GPS, which can then be compared to the TG time series, but only for short time series and in limited locations (e.g. Han et al., 2014; Wöppelmann et al., 2014). In this study we therefore focus on how much of the regional sea-level measurements can be explained without or before the use of GPS. Tide gauge measurements that are clearly affected by vertical land motions are therefore discarded (Sect. 2.1).

To determine the spatial patterns of the different contributing processes, observations from various sources are used in combination with models (Sect. 2.2). For the steric variations, temperature and salinity profiles are used, and these have been extrapolated to a spatial pattern by Levitus et al. (2012). To obtain the resulting change in sea-surface height, we use the approach by Landerer et al. (2007) to include the effect of changes in bottom pressure. For all processes dealing with mass changes - land ice and terrestrial changes - a gravitationally consistent sea-level model is used to compute the spatial pattern of sea-level change (e.g. Woodward, 1887; Farrell and Clark, 1976; Mitrovica et al., 2001). This model requires spatial information on, for instance, the glacier melt, which restricts the number of data sets that can be used. This fact, combined with the historical period considered in IPCC AR4 (Bindoff et al., 2007), leads to the choice for the 19612003 period. Finally, we combine the sea-level patterns following Slangen et al. (2012, 2014), which results in a map of net regional sea-level trends. All changes shown are relative sea-level changes, which is defined as the difference between the ocean floor and the ocean surface.

Going back in time, reliable observations of sea-level change and of the contributions become sparser, which leads to larger uncertainties. Nevertheless it is interesting to look at the TG data, because they cover a much longer period than satellite data, and therefore short-term variability will likely have less impact on trends based on these time series.

The central questions of this study are how well can this set of contributing processes explain the TG observations, and are there processes which are leading the explanation of regional sea-level trends? We show the regional patterns of the various processes (Sect. 3.1), compare both individual TG observations and regional averages (Sects. 3.2, 3.3), and examine the effect of variations in the individual contributions (Sect. 4.1). Global mean budget closure is discussed in Sect. 4.2, and finally the conclusions are summarised in Sect. 5.

\section{Data and methodology}

\subsection{Tide gauge stations}

We use annual mean Revised Local Reference tide gauge (TG) data from the PSMSL data base (Holgate et al., 2013, http://www.psmsl.org), all documentation checked and updated on 11 April 2014.

First, all the stations which contain at least 20 yearly values in the period 1961-2003 are selected. Then, we select those TG stations which were carefully checked by Church et al. (2004) and Church and White (2011), in order to eliminate unreliable stations. In addition, we use checked annual time series of 13 TG stations in the German Bight area (Dangendorf et al., 2013). Finally, a linear regression is performed to calculate the average trend for each station:

$$
h(t)=\underbrace{\beta_{0}}_{\text {mean level }}+\underbrace{\beta_{1} t}_{\text {trend }}+\underbrace{a \sin \left(\frac{2 \pi t}{18.6}\right)+b \cos \left(\frac{2 \pi t}{18.6}\right)}_{\text {nodal cycle }} .
$$

The regression includes the effects of the 18.6-year nodal cycle, which is one of the components driving the tides on earth and influencing the tidal amplitude on longer timescales (Baart et al., 2012). Although the $R^{2}$ is 0.98 when comparing the trends including and excluding nodal effects, locally the inclusion of the nodal cycle may lead to a doubling of the trend. In Eq. (1), $h$ is the annual mean sea level at time $t$ in years, $\beta_{0}$ is the sea level at $t=0, \beta_{1}$ the average rise per year, and $a$ and $b$ are nodal-cycle-related values which are calculated separately for each TG station. Solving Eq. (1) results in a set of trends $\left(\beta_{1}\right)$ at 285 stations (Table 1 ), with values between -8.1 and $6.9 \mathrm{~mm} \mathrm{yr}^{-1}$. These values are not corrected for GIA, because GIA will be considered as a separate regional sea-level contribution.

Uncertainties in the TG time series may not only arise from vertical land movements due to tectonics or GIA, but also from changes in the surroundings of the TG, which are often located in or near harbour areas. Although stations with large and sharp datum shifts have been eliminated, stations experiencing smaller or more gradual datum shifts may still be included. To decrease the influence of these local effects, the stations are not only examined locally (Sect. 3.2), but also per region (Sect. 3.3), which is based on a common ocean basin or coastline in the first place, and correlation within the regions in the second place (Fig. 1).

\subsection{Contributing processes}

The following contributions to sea-level change are included in this study: land ice, steric, GIA, terrestrial water storage and atmospheric loading (AL). Regional patterns of all processes are needed to compare them to the TG observations. While these patterns are all based on observations, we will refer to them as "contributions" or "models" as not to confuse 
Table 1. Station codes of 285 tide gauge stations (RLR) included in the analysis (Holgate et al., 2013, http://www.psmsl.org).

\begin{tabular}{lll}
\hline Region & \# records & PSMSL Station ID \\
\hline 1 & 8 & $166 ; 175 ; 193 ; 225 ; 384 ; 487 ; 829 ; 984$ \\
2 & 12 & $10 ; 127 ; 158 ; 245 ; 256 ; 377 ; 437 ; 508 ; 795 ; 1196 ; 1325 ; 1394$ \\
3 & 11 & $155 ; 300 ; 523 ; 539 ; 598 ; 756 ; 1329 ; 1371 ; 1372 ; 1397 ; 1450$ \\
4 & 37 & $12 ; 96 ; 112 ; 135 ; 180 ; 183 ; 195 ; 234 ; 235 ; 299 ; 311 ; 332 ; 351 ; 360 ; 362 ; 366 ; 367 ; 392 ; 395 ; 396 ;$ \\
& & $399 ; 412 ; 427 ; 429 ; 430 ; 519 ; 525 ; 597 ; 636 ; 848 ; 886 ; 1068 ; 1111 ; 1153 ; 1158 ; 1295 ; 1299$ \\
5 & 13 & $188 ; 199 ; 246 ; 497 ; 520 ; 563 ; 690 ; 759 ; 1038 ; 1106 ; 1107 ; 1193 ; 1297$ \\
6 & 6 & $163 ; 511 ; 544 ; 571 ; 844 ; 1472$ \\
7 & 6 & $431 ; 433 ; 501 ; 819 ; 832 ; 1271$ \\
8 & 46 & $1 ; 3 ; 7 ; 9 ; 20 ; 22 ; 23 ; 24 ; 25 ; 32 ; 52 ; 58 ; 95 ; 236 ; 255 ; 286 ; 302 ; 303 ; 334 ; 413 ; 432 ; 468 ;$ \\
& & $469 ; 470 ; 483 ; 484 ; 489 ; 638 ; 754 ; 755 ; 763 ; 936 ; 982 ; 1294$ \\
9 & \multirow{4}{*}{25} & $2 ; 13 ; 64 ; 70 ; 72 ; 76 ; 80 ; 81 ; 82 ; 89 ; 91 ; 98 ; 113 ; 119 ; 120 ; 179 ; 289 ; 397 ; 643 ; 644 ; 645 ; 762 ; 789 ; 1197 ; 1236$ \\
10 & 19 & $14 ; 57 ; 68 ; 69 ; 71 ; 78 ; 79 ; 88 ; 122 ; 172 ; 194 ; 203 ; 229 ; 239 ; 240 ; 249 ; 285 ; 315 ; 376$ \\
11 & 15 & $61 ; 154 ; 168 ; 352 ; 353 ; 410 ; 496 ; 498 ; 685 ; 760 ; 761 ; 960 ; 1075 ; 1239 ; 1468$ \\
12 & 5 & $43 ; 205 ; 414 ; 438 ; 596$ \\
13 & 68 & $132 ; 159 ; 174 ; 394 ; 449 ; 460 ; 513 ; 522 ; 528 ; 537 ; 540 ; 545 ; 546 ; 595 ; 614 ; 661 ; 679 ; 721 ; 724 ; 727 ; 753 ;$ \\
& & $810 ; 811 ; 813 ; 824 ; 845 ; 912 ; 933 ; 934 ; 955 ; 997 ; 1007 ; 1064 ; 1094 ; 1095 ; 1097 ; 1100 ; 1101 ; 1102 ; 1103 ;$ \\
& & $1104 ; 1108 ; 1147 ; 1148 ; 1149 ; 1151 ; 1155 ; 1194 ; 1217 ; 1248 ; 1251 ; 1252 ; 1265 ; 1275 ; 1318 ; 1351 ; 1365 ;$ \\
& & $1370 ; 1386 ; 1388 ; 1391 ; 1445 ; 1446 ; 1449 ; 1452 ; 1470 ; 1473 ; 1489$ \\
14 & 14 & $111 ; 150 ; 189 ; 196 ; 221 ; 500 ; 564 ; 637 ; 825 ; 834 ; 935 ; 1115 ; 1154 ; 1157$ \\
\hline
\end{tabular}

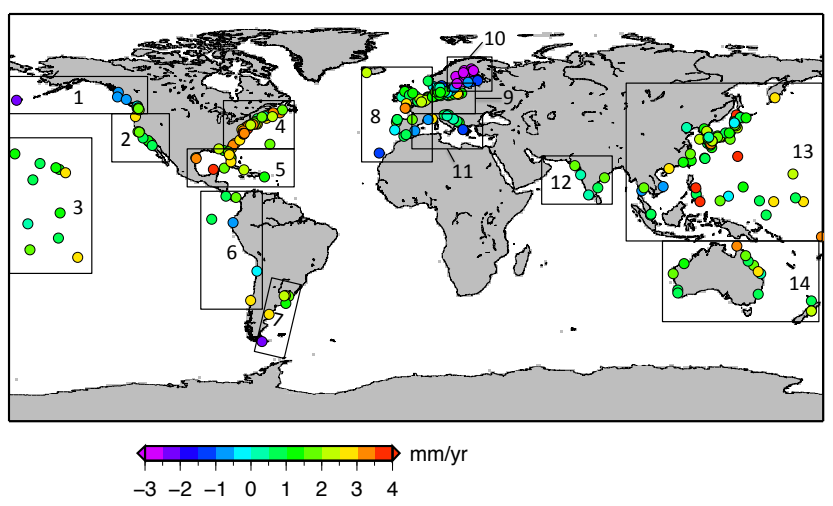

Figure 1. Tide gauge trends $\left(\mathrm{mm} \mathrm{yr}^{-1}\right)$ for the period 1961-2003; 285 checked records with each at least 20 years of data are sorted into 14 regions. Data are from the PSMSL data base (Holgate et al., 2013). Region 12 contains the least records (5), region 13 the most (68).

them with the TG observations. All contributions shown are on a $1 \times 1$ degree grid.

For the contributions of the Greenland Ice Sheet (GIS) and the Antarctic Ice Sheet (AIS), the surface mass balance is estimated using output from regional climate model RACMO2 (Ettema et al., 2009; Lenaerts et al., 2012). The dynamical component for both ice sheets is based on data from Rignot et al. (2011). For the glaciers and ice caps (GIC), Dyurgerov and Meier (2005) provide mass balance estimates of 13 GIC regions across the world. This is not the most recent estimate, but it is the only one that provides region-specific mass change. Compared to the more recent global mean value of
Cogley (2009a), the difference is less than $10 \%$, and within the uncertainty range given by Dyurgerov and Meier (2005).

The land water storage change contribution is constructed using an estimate for past groundwater depletion (Wada et al., 2012) and water storage behind dams (Chao et al., 2008).

To model the variations in regional sea level from all mass contributions, we use a sea-level model (Schotman and Vermeersen, 2005), which incorporates gravitational, rotational and solid-earth deformation effects. The model solves the sea-level equation (Farrell and Clark, 1976) using a pseudospectral approach (Mitrovica and Peltier, 1991). The earth model is based on PREM (Dziewonski and Anderson, 1981), and is elastic, compressible and radially stratified.

Volume changes due to local variations in temperature and salinity of the ocean are referred to as the steric contribution. In this study we use the pentadal gridded $(1 \times 1$ degree, 16 depth layers) temperature and salinity data of Levitus et al. (2012) for the steric change in the upper $2000 \mathrm{~m}$ of the ocean (Supplement Fig. S1e, data downloaded June 2013). Other steric data sets, such as Domingues et al. (2008) or Ishii and Kimoto (2009) do not provide gridded data below $700 \mathrm{~m}$ depth. We use Purkey and Johnson (2010) for the steric change below $2000 \mathrm{~m}$ (Supplement Fig. S1f, $0.5 \times 0.5$ degree regridded to $1 \times 1$ degree, 5 depth layers). Although Purkey and Johnson (2010) presented estimates only for the period 1990-2000, we assume that the rate of change is valid for the entire period 1961-2003, since the deep ocean responds much slower to changes in the atmosphere than the upper ocean. 
The steric variations are translated into changes in sea surface height ( $\mathrm{SSH}$ ) using bottom pressure anomalies, computed with the method presented in Landerer et al. (2007). Their theory states that each depth layer gains mass from the expansion of lower layers, and loses mass due to its own expansion and that of the layers above. As a result, shallower oceans will rise more due to increased bottom pressure, while in the deep ocean the bottom pressure is decreased, leading to a smaller SSH change. Following their Eq. (3), we first compute the bottom pressure anomaly for each depth layer, using the area of each layer, the total ocean area, and the global mean steric anomaly of each layer. For each ocean grid point, the bottom pressure anomaly is summed over the available depth layers (Supplement Fig. S1g). Finally, the SSH change at each grid point is computed by adding the bottom pressure anomaly to the steric change.

GIA is the response of the solid earth to the loading and unloading of large ice masses on 1000-year timescales. We use the present-day contribution of GIA to sea level as computed by the ICE-5G(VM2) model (Peltier, 2004). It is assumed to be constant in time over the period studied. A comparison to another GIA product is provided in Sect. 4.1.

An increase of $1 \mathrm{mbar}$ in pressure at the ocean surface will cause a sea-level fall of $1 \mathrm{~cm}$ (Ross, 1854; Wunsch and Stammer, 1997). Using monthly mean sea-level pressure (SLP) data from the NCEP/NCAR reanalysis project (Kalnay et al., 1996), we compute the trend in SLP between 1961 and 2003 after removing the ocean-only global mean SLP, from which the resulting AL effect can be computed.

\section{Comparing observations to contributions}

\subsection{Spatial patterns of the contributions}

The spatial patterns of the contributions are shown in Fig. 2, and their associated uncertainties in Fig. 3. For reference, the ice sheet, terrestrial storage and SSH contributions are broken down into their respective components in Supplement Fig. S1.

The regional sea-level change due to mass changes on the AIS and GIS in $\mathrm{mm} \mathrm{yr}^{-1}$ for the period 1961-2003 (Fig. 2a), and for GIC melt (Fig. 2b) both display a characteristic gravitational signal (e.g. Mitrovica et al., 2001). Due to the loss of land ice mass, the gravitational attraction of the ice weakens, causing a sea-level fall close to the ice, while locations at a distance further than $2200 \mathrm{~km}$ experience a sea-level rise, and further than $6700 \mathrm{~km}$ a sea-level rise above the global mean. Since most of the changing land ice is located at high latitudes, the largest sea-level rise will therefore occur in the equatorial regions. The uncertainties associated with these contributions (Fig. 3a, b) are largest at the source of the melt, with another maximum in the far field due to the gravitational effect. Of these three contributions, the AIS has the largest uncertainty. a) Ice sheets

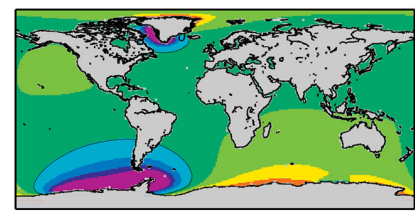

c) Steric SSH

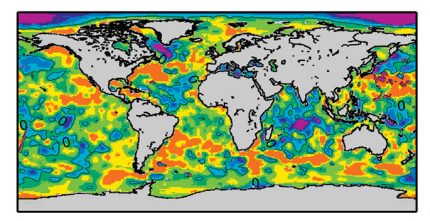

e) Atmospheric pressure change

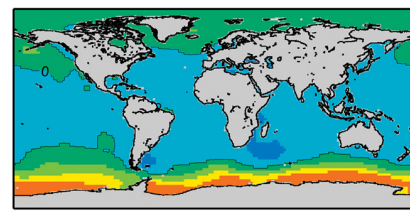

mm/yr

$-2.0-1.5-1.0-0.5 \quad 0.0 \quad 0.5 \quad 1.0 \quad 1.5 \quad 2.0$ b) Glaciers and ice caps

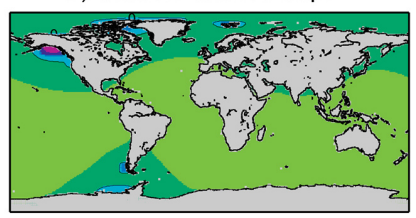

d) Glacial isostatic adjustment

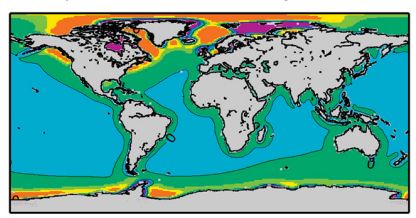

f) Terrestrial storage change

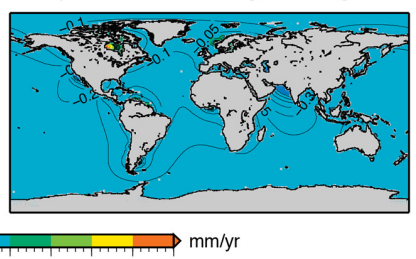

Figure 2. Regional sea-level trends $\left(\mathrm{mm} \mathrm{yr}^{-1}\right)$ over the period 1961-2003 for the following contributions; (a) ice sheets, (b) glaciers and ice caps, (c) steric change, (d) glacial isostatic adjustment, (e) atmospheric pressure loading, and (f) terrestrial water storage change from groundwater extraction and reservoir impoundment. The black line is zero-contour, except in (f) where every 0.05 contour is shown for clarity. This accompanies the global mean trends in Table 2 . All data are on a $1 \times 1$ degree grid, with an ocean surface area of $3.50 \times 10^{14} \mathrm{~m}^{2}$.

The steric contribution (Fig. 2c, Levitus et al., 2012; Purkey and Johnson, 2010; Landerer et al., 2007), shows a spatially highly variable pattern, in contrast to the land ice contributions. This is because this contribution incorporates local changes in temperature and salinity, a process that is influenced by oceanic and atmospheric dynamics. The figure also shows a sharp sea-level fall over some parts of the deep ocean, such as east of Japan, which is due to the ocean bottom pressure correction (Supplement Fig. S1g). The SSH uncertainties (Fig. 3c) are dominated by the relatively large uncertainties in the deep ocean, and are the largest source of error together with the AIS.

The GIA pattern (Fig. 2d) shows the largest effects near the former locations of the Laurentide and Fennoscandian ice sheets, but is close to zero over large parts of the ocean elsewhere (Peltier, 2004). The GIA uncertainties (Fig. 3d) are estimated to be around $20 \%$, based on differences between various GIA models, which leads to the largest uncertainties in the vicinity of the former ice sheets and small uncertainties elsewhere.

The AL pattern (Fig. 2e) shows a strong meridional signal, indicating a decrease of pressure near the poles and an increase in equatorial regions (Wunsch and Stammer, 1997). 
a) Ice sheets

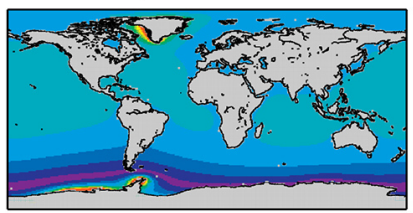

c) Steric SSH

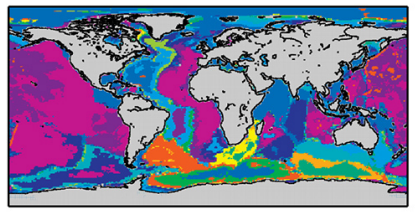

e) Atmospheric pressure change

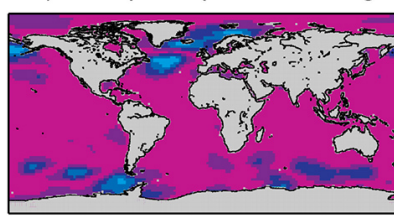

0.0 b) Glaciers and ice caps

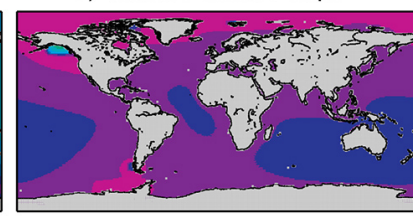

d) Glacial isostatic adjustment

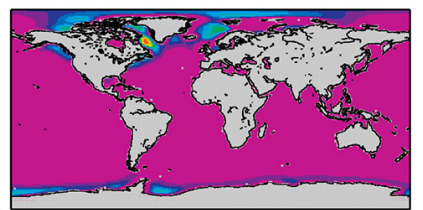

f) Terrestrial storage change

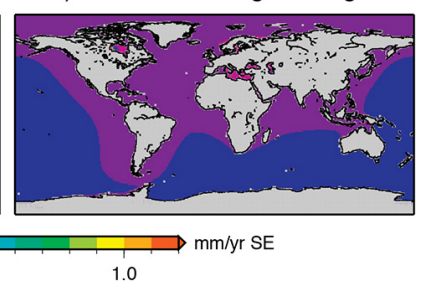

Figure 3. Regional sea-level uncertainties $\left(\mathrm{mm} \mathrm{yr}^{-1}\right)$ over the period 1961-2003 for (a) ice sheets, (b) glaciers and ice caps, (c) steric change, (d) glacial isostatic adjustment, (e) atmospheric pressure loading, and (f) terrestrial water storage change from groundwater extraction and reservoir impoundment. Accompanying global mean values in Table 2 .

The associated uncertainties are generally small (Fig. 3d), but can reach up to $0.4 \mathrm{~mm} \mathrm{yr}^{-1}$ locally.

The contribution of water impoundment behind dams is larger than the groundwater depletion for the period 19612003, and thus the net terrestrial contribution is negative, resulting in a largely negative pattern (Fig. 2f). Similar to the land ice contribution, sea levels fall near regions of mass loss on land, in other words the regions where groundwater depletion takes place, for instance near the Indian coast, and sea levels rise near areas of mass gain due to dam construction, for instance around South America (see also Fiedler and Conrad, 2010). Uncertainties (Fig. 3f) are largest at the source of mass change and in the far field, similar to the land ice contributions.

When all the contributions are combined, the net regional pattern (Fig. 4, upper panel, observed TG included for comparison) indicates a positive trend in sea-level change for the majority of the ocean over the period 1961-2003. The net uncertainties (Fig. 4, lower panel) are generally smaller than the net contribution, except in regions close to ice melt regions, where sea-level change is small or negative and uncertainties are relatively large. Near the tide gauges, most uncertainties are between 0.5 and $0.8 \mathrm{~mm} \mathrm{yr}^{-1}$. The patterns show influences from the different contributions: the steric component is clearly present with its small-scale variability, but GIA influences show up around Svalbard for instance, and

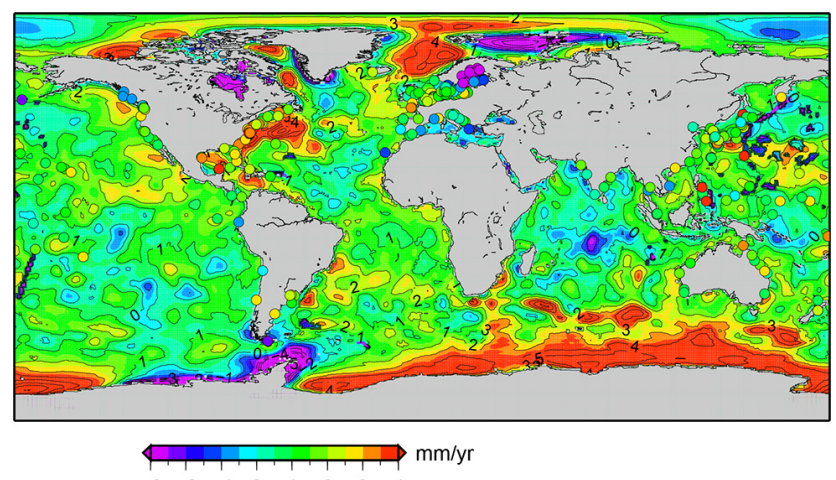

$\begin{array}{llllllll}-3 & -2 & -1 & 0 & 1 & 2 & 3 & 4\end{array}$

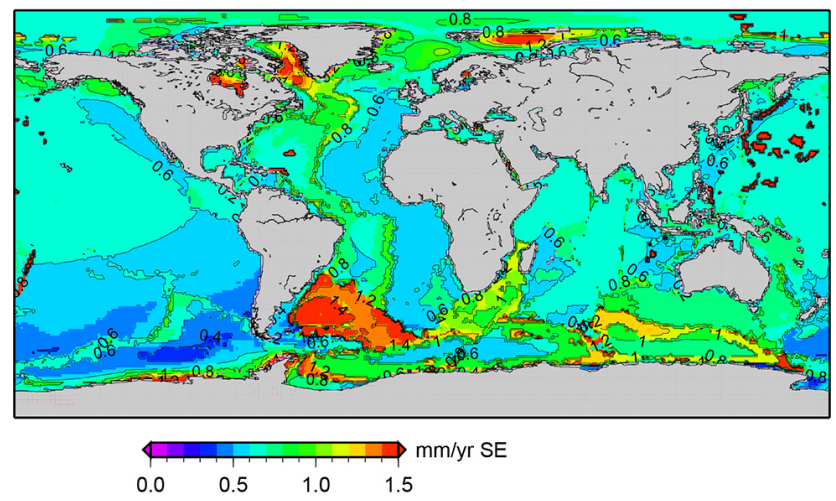

Figure 4. Upper panel: net trend in sea-level change $\left(\mathrm{mm} \mathrm{yr}^{-1}\right)$ over the period 1961-2003, including all the contributions as shown in Fig. 2. Tide gauge trends in filled circles. Lower panel: uncertainties $(1 \sigma)$ in the net sea-level change trend $\left(\mathrm{mm} \mathrm{yr}^{-1}\right)$.

there is sea-level fall due to land ice melt near the two large ice sheets.

The net global mean values of all the contributions (Table 2) compared to the IPCC AR4 global mean trend for the same period (Bindoff et al., 2007) show a difference in the mean, but within the $1 \sigma$ uncertainty interval. Section 4.2 will compare these values to Church et al. (2011), who closed the global mean sea-level budget for a different time period.

\subsection{Local comparison}

Figure 5 shows regions 1 to 5 . In region 1 , the northernmost TG shows a negative trend, which is also present in the models due to the melt of Alaskan glaciers (Fig. 2b). The positive trends towards the south and further offshore (0.4$1.1 \mathrm{~mm} \mathrm{yr}^{-1}$ ) are a combination of the steric (Fig. 2c) and the long-term GIA (Fig. 2d) contributions. The TG in the west falls by $-2.1 \mathrm{~mm} \mathrm{yr}^{-1}$, and cannot be explained with this set of contributions.

The TG in region 2 all show positive trends, ranging from 0.7 to $2.8 \mathrm{~mm} \mathrm{yr}^{-1}$. The nearest model points are in the range of $0.8-2.2 \mathrm{~mm} \mathrm{yr}^{-1}$. The steric contribution is between 0 and $1 \mathrm{~mm} \mathrm{yr}^{-1}$, which is only slightly increased by the land ice contributions, GIA and AL. 
Table 2. Global mean sea-level trends $\left(\mathrm{mm} \mathrm{yr}^{-1} \pm 1 \sigma\right.$ ) of the various contributions for 1961-2003; compared to Church et al. (2011) trends for 1971-2008, as discussed in Sect. 4.2.

\begin{tabular}{lrlr}
\hline Contribution & $\begin{array}{r}\text { This study } \\
(1961-2003) \\
\left(\mathrm{mm} \mathrm{yr}^{-1}\right)\end{array}$ & Reference & $\begin{array}{r}\text { Church et al. (2011) } \\
(1971-2008) \\
\left(\mathrm{mm} \mathrm{yr}^{-1}\right)\end{array}$ \\
\hline AIS & $0.19 \pm 0.44$ & Lenaerts et al. (2012); Rignot et al. (2011) & $0.30 \pm 0.20$ \\
GIS & $0.14 \pm 0.16$ & Ettema et al. (2009); Rignot et al. (2011) & $0.12 \pm 0.17$ \\
GIC & $0.52 \pm 0.18$ & Dyurgerov and Meier (2005) & $0.67 \pm 0.03$ \\
Steric SSH & $0.62 \pm 0.32$ & Levitus et al. (2012); Purkey and Johnson (2010) & $0.80 \pm 0.15$ \\
Atm. pressure & $0.00 \pm 0.02$ & Kalnay et al. (1996) & - \\
Dams & $-0.55 \pm 0.17$ & Chao et al. (2008) & $-0.44 \pm 0.15$ \\
Groundwater & $0.35 \pm 0.10$ & Wada et al. (2012) & $0.26 \pm 0.07$ \\
GIA & $0.00 \pm 0.03$ & Peltier (2004) & - \\
\hline Sum & $1.29 \pm 0.70$ & & $1.78 \pm 0.36$ \\
Observations & $1.80 \pm 0.50$ & IPCC AR4 (Bindoff et al., 2007) & $1.83 \pm 0.18$ \\
\hline
\end{tabular}

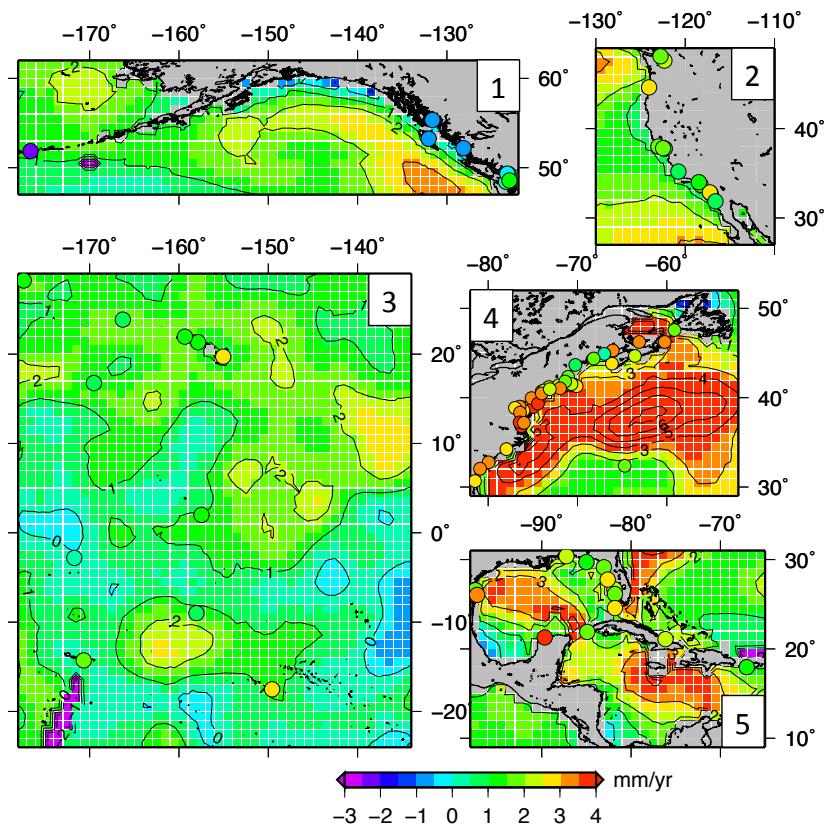

Figure 5. Trends in sea-level change $\left(\mathrm{mm} \mathrm{yr}^{-1}\right)$ over the period 1961-2003, for regions (1) Gulf of Alaska, (2) West coast USA, (3) North Pacific Ocean, (4) East coast USA, and (5) the Caribbean. Zoom of Fig. 4. Regions indicated in Fig. 1.

The steric contribution is the leading pattern in explaining the observations in region 3 . All TG trends are positive, up to $2.9 \mathrm{~mm} \mathrm{yr}^{-1}$, and the associated grid points are positive but display lower values, up to $1.9 \mathrm{~mm} \mathrm{yr}^{-1}$.

In region 4 we observe high positive trends in both TG and models, due to large steric (Fig. 2c) and GIA (Fig. 2d) contributions. The TG range from 0.5 to $4.6 \mathrm{~mm} \mathrm{yr}^{-1}$, while the associated grid points are between 1.5 and $4.2 \mathrm{~mm} \mathrm{yr}^{-1}$. The TG tend to show larger trends in the south, which is also visible in the models.
Region 5 shows only positive TG trends, and along the coast of Florida they are reproduced by the models. There are two TGs in the west of the region located close to each other, with very different trends, 1.6 vs. $3.1 \mathrm{~mm} \mathrm{yr}^{-1}$. The nearest model point indicates a trend of $3.3 \mathrm{~mm} \mathrm{yr}^{-1}$, which fits better with the higher value. However, there is a strong gradient in the steric contribution here, which might explain these large local differences.

Figure 6 shows regions 6 to 8 . Only part of the observed trends in region 6 can be explained. The two negative TGs on the coast of Peru and Chile are $\sim 1.6 \mathrm{~mm} \mathrm{yr}^{-1}$ off, while the southernmost gauge displays a very large trend of $2.7 \mathrm{~mm} \mathrm{yr}^{-1}$, while the models are very small. Because this region is relatively far from the ice melt regions, the steric contribution is strongest here.

The observed negative trend in the south of region 7 is $0.8 \mathrm{~mm} \mathrm{yr}^{-1}$ lower than the nearest point in the contributions, but both show a strong negative trend due to the Antarctic melt. However, in the north the trends in the observations range from 1.1 to $2.9 \mathrm{~mm} \mathrm{yr}^{-1}$, while the models indicate trends around $0.5 \mathrm{~mm} \mathrm{yr}^{-1}$.

Most of the trends observed in region 8 match rather well with the models. The pattern in this region is determined by the steric contribution in combination with GIA. However, there is a negative trend of $-1.0 \mathrm{~mm} \mathrm{yr}^{-1}$ at the Canary Islands, which is not captured by the models.

Regions 9 to 12 are shown in Fig. 7. Region 9 is just outside the GIA uplift region in the Baltic, in contrast to region 10 , which is heavily influenced by GIA uplift. In both regions, the agreement between the observations and net contributions is high due to the absence or presence of GIA, with mostly positive values in region 9 and negative values in region 10.

In the Mediterranean (region 11), the observations range between -1.3 and $3.2 \mathrm{~mm} \mathrm{yr}^{-1}$. Nevertheless, the contributions match the observations better than might be expected 


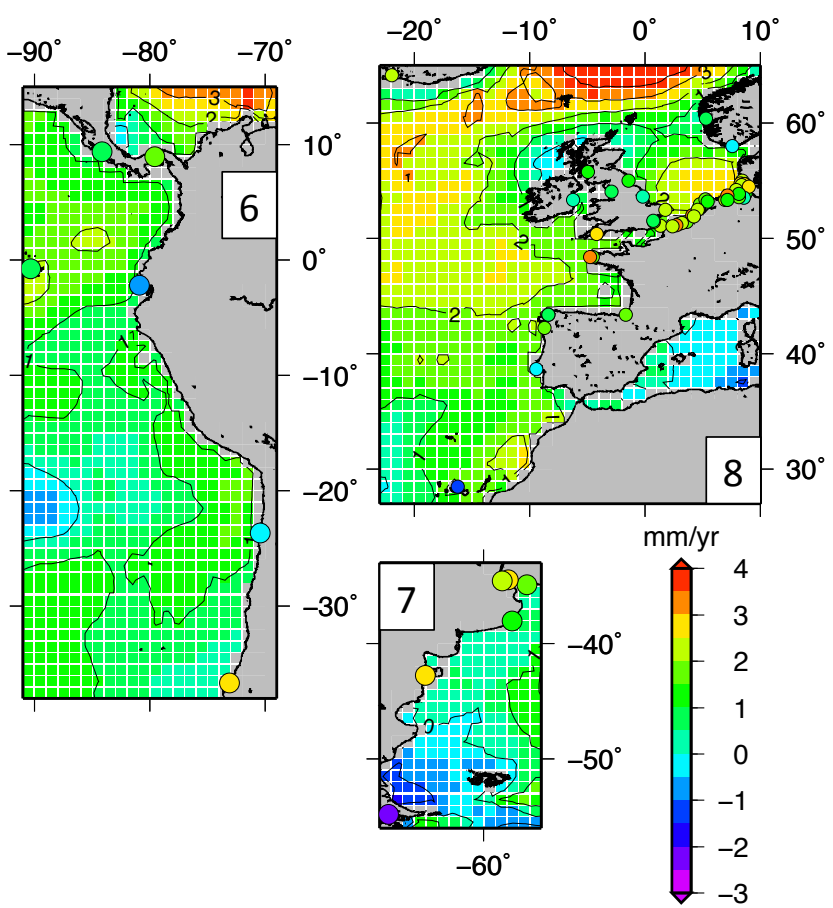

Figure 6. Trends in sea-level change $\left(\mathrm{mm} \mathrm{yr}^{-1}\right)$ over the period 1961-2003, for regions (6) South American west coast, (7) South American east coast, and (8) European coast. Zoom of Fig. 4. Regions indicated in Fig. 1.
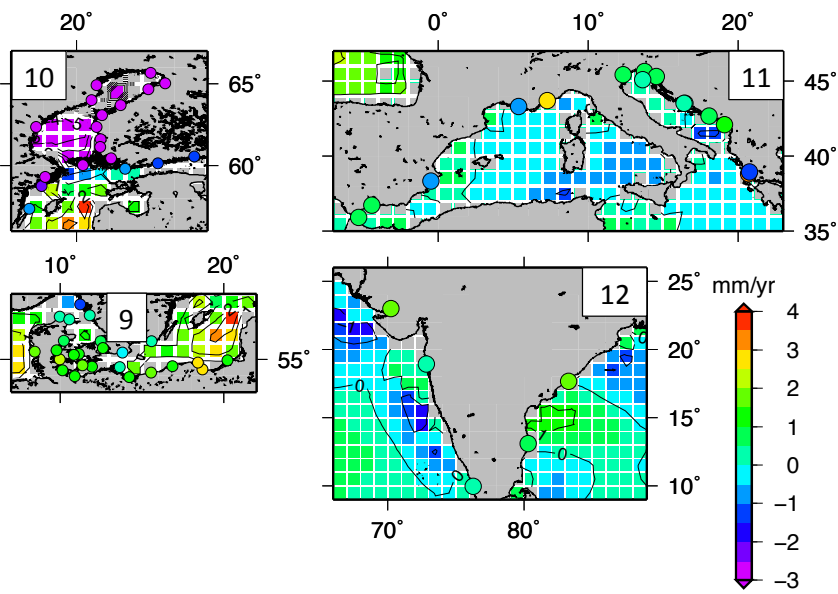

Figure 7. Trends in sea-level change $\left(\mathrm{mm} \mathrm{yr}^{-1}\right)$ over the period 1961-2003, for regions (9) Baltic South, (10) Baltic North, (11) Mediterranean, and (12) India. Zoom of Fig. 4. Regions indicated in Fig. 1.

from a shallow sea with more complicated mechanics such as the Mediterranean (e.g. Pirazzoli, 2005; Gomis et al., 2008; Tsimplis et al., 2011). The above-average values in the landice contributions are not compensated by the lower contributions of steric, GIA, AL and terrestrial, leading to low model values.
The TG around India, in region 12, range between 0.3 and $1.8 \mathrm{~mm} \mathrm{yr}^{-1}$. The models tend to be lower, with values between -0.2 and $0.9 \mathrm{~mm} \mathrm{yr}^{-1}$. This is due to the large groundwater extraction in this region (Fig. 2f). A possible explanation for the observation-model discrepancy could be large subsidence, which is often a consequence of the extraction of groundwater (Holzer and Johnson, 1985), and not included in these models.

Figure 8 shows regions 13 and 14. Region 13 contains the largest number of observations (68 records), of which the majority is located along the Japanese coast. Most of the TG trends are positive, although the variation is large and covers a wide range between -1.1 and $6.9 \mathrm{~mm} \mathrm{yr}^{-1}$. The models also show large variations, albeit on a smaller range, between -1.5 and $2.5 \mathrm{~mm} \mathrm{yr}^{-1}$. Some of the TG indicate very high trends, not reproduced by the models. However, for this specific region, it is important to keep in mind that this is a tectonically active region, which influences the TG measurements. Even though records with sharp jumps are removed, earthquakes may cause crustal movements on longer timescales as well, which contaminates the TG signal.

The TG indicate positive trends in region 14 . This is also shown in the models: the trends are large because this region is in the far field of the land ice melt signal (Fig. 2a, b), and mostly experiences a positive steric contribution (Fig. 2c). Although the range of both observed and modelled changes is similar, they are distributed differently around the $15 \mathrm{TG}$ sites.

In conclusion we see that, although observed values may not be captured exactly, the observations and models often fall within in a similar range. Both GIA and the steric contribution explain large parts of the observations. Especially in regions with strong GIA, the agreement between TG and models is good. Generally, TG values show larger variability than the model values, indicating that the models are probably too coarse to fully capture local changes, or that maybe there is a process missing. To partly eliminate the local effect, the next section will focus on regional averages.

\subsection{Regional comparison}

The individual values are now sorted in 14 regions, and a mean and standard deviation is computed for each region (Fig. 9a), showing the observations in blue and the average of the nearest model points in red. In all regions, the observed mean $\pm 1 \sigma$ and the model mean $\pm 1 \sigma$ overlap at least partially. A good agreement between regional tide-gauge observations and models is found in regions 3, 4, 5, 6, 8, 9 and 14, with differences less than $0.3 \mathrm{~mm} \mathrm{yr}^{-1}$. This indicates that, although the point-by-point comparison may not be perfect, the models do capture the regional tendency quite well. With differences between 0.4 and $0.7 \mathrm{~mm} \mathrm{yr}^{-1}$, regions $2,11,12$ and 13 are not as good, but still reasonable. Only in three regions are the differences larger than $0.9 \mathrm{~mm} \mathrm{yr}^{-1}(1,7,10)$. However, if we look at the relative difference with respect to 


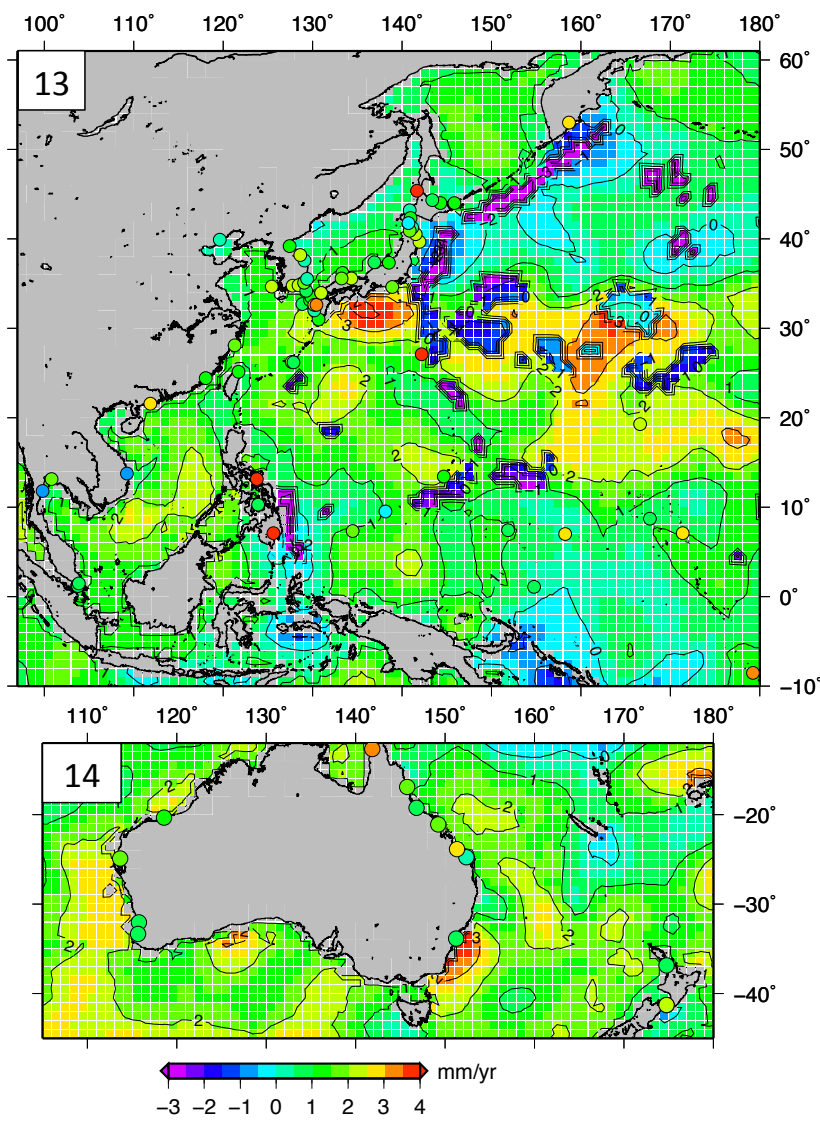

Figure 8. Trends in sea-level change $\left(\mathrm{mm} \mathrm{yr}^{-1}\right)$ over the period 1961-2003, for regions (13) Asian Pacific and (14) South Pacific West. Zoom of Fig. 4. Regions indicated in Fig. 1.

the mean of the TG observations, region 10 actually shows a rather good match, with only a $20 \%$ difference. In region 1 , the modelled pattern shows a strong gradient towards the open sea due to glacier melt and GIA. Since at each TG the nearest ocean value is taken from the net contributions, this leads to an overestimation in the net contribution average. There is also a large difference between the observed and model mean in region 7 . While in this region there is mostly an agreement on the sign between observations and models, the values in the models are much smaller than the observed values. This is due to the modelled land ice contribution, which causes a large gradient at the South American coast (Fig. 2a, b). Overall, Fig. 9a shows that on a regional scale the models can explain the observations reasonably well in most of the regions.

In Fig. 9b, the regional values are denoted by the red crosses, and the individual values in black crosses. The individual values are scattered around the regional mean values, displaying a large variability within the regions, which is represented by the regional standard deviation. A linear least squares regression on the regional values results in the solid green line, which has an $R^{2}$ value of 0.87 , and a regres-

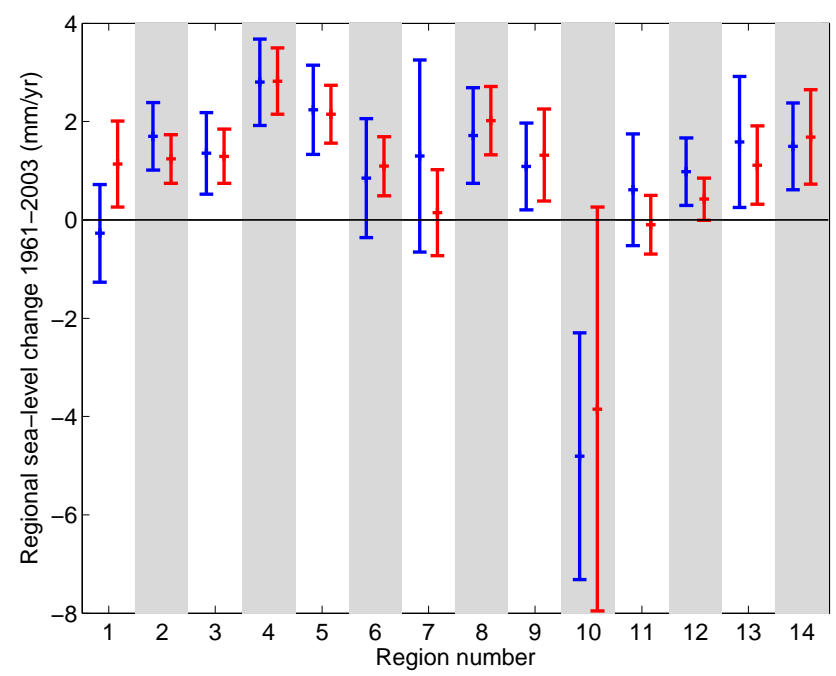

Figure 9a. Regional comparison of TG observations (blue) and associated model points (red) $\left(\mathrm{mm} \mathrm{yr}^{-1}\right)$, error bars indicate $1 \sigma$ standard deviation within the regions. Region numbers as in Fig. 1.

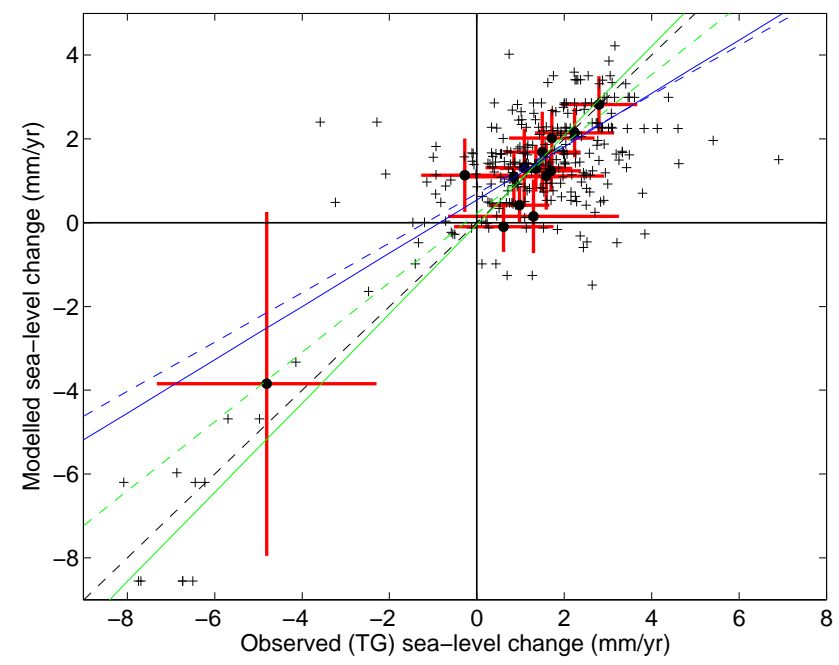

Figure 9b. Tide gauge observations versus models $\left(\mathrm{mm} \mathrm{yr}^{-1}\right)$ : (red) regional mean $\pm 1 \sigma$ standard deviation within the regions; (black) individual values. Linear least squares fit for (green-solid) all regional means, (green-dashed) regional means except region 10, (blue-solid) all local values, and (blue-dashed) local values except region 10 .

sion coefficient of 1.07. For the individual values, the $R^{2}$ is 0.61 and the regression coefficient 0.83 , shown by the dashed green line. This means that the models slightly overestimate the regional values, but underestimate the individual measurements more. It also demonstrates that the regional values are better captured than the individual values. We note that these results are heavily influenced by the inclusion of region 10, the Northern Baltic. Without this region, the regional $R^{2}$ drops to 0.46 , although the regression coefficient is still 0.64 (solid blue line). For the local values, the $R^{2}$ is 


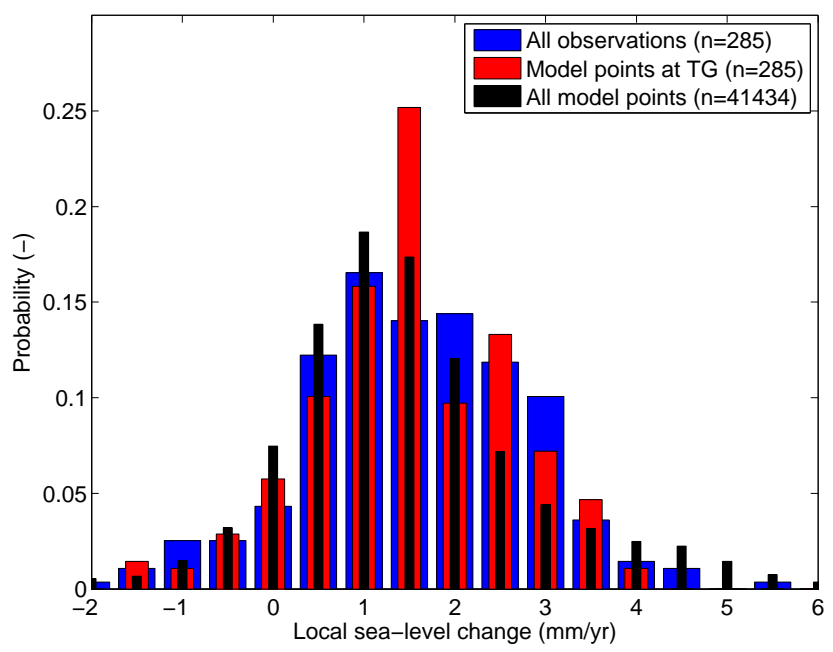

Figure 10. Histogram of the tide gauge values (blue), associated model points (red), and all ocean grid points (black). Bin width $=$ $0.5 \mathrm{~mm} \mathrm{yr}^{-1}$. Percentage of each series below $-2 \mathrm{~mm} \mathrm{yr}^{-1}$ is 5.8 , 4.3 and $2.4 \%$, respectively. Percentage above $6 \mathrm{~mm} \mathrm{yr}^{-1}$ is $0.4,0$ and $0.3 \%$, respectively.

only 0.25 and the regression coefficient 0.59 , which means that about half of the measurements can be explained by the models (dashed blue line).

Figure $9 \mathrm{a}$ and $\mathrm{b}$ also show that the variability in the TG observations is mostly larger than in the net contributions. There may be several reasons for the smaller range in the net contributions. It might be caused by the relatively coarse spatial resolution of the grid, since the net contributions are computed on a $1 \times 1$ degree grid, averaging all contributions within the grid box and neglecting sub-grid variability. However, it may also indicate that there is a process missing from the contributions, which might not be directly related to climate change, such as subsidence, local sedimentary processes or tectonics. These particular processes, acting on a small local scale, may be responsible for the larger spread in TG observations.

Figure 10 shows a histogram of the individual TG observations (blue, 285 points), models at the TG locations (red, 285 points) and all model points (black, 41434 points). The maximum of the TG is in the $1 \mathrm{~mm} \mathrm{yr}^{-1}$ bin, as is the maximum for all model points. For the model points near the TG, the maximum is in the $1.5 \mathrm{~mm} \mathrm{yr}^{-1}$ bin, and they have the smallest total range and a large central value. The TG have slightly longer tails and a flatter shape, thus indicating a larger variability for the TG. The series showing all model points has a long tail of lower values, which is due to the inclusion of land ice patterns with negative values close to the ice melt regions. The difference between the red and black series indicates that the locations where the TG are located are not fully representative for the entire ocean surface area, which is not surprising since the TG are generally located at the coast and heavily biased towards the Northern Hemisphere.

\section{Discussion}

\subsection{Varying the contributions}

So far, the fields of the different contributions have remained unchanged throughout this study. In this section however, the dependency of the results on the estimates of the contributions used in the previous section will be examined in order to see how changes in the individual contributions affect the explained variance.

As a simple test, each of the contributions is varied by scaling them by 50 and $150 \%$, one contribution at a time. We find that the regional $R^{2}(0.87$ in Sect. 3.3) varies between 0.81 and 0.90 , with the exception of a $50 \%$ reduction in GIA, which led to an $R^{2}$ of only 0.62 . The regression coefficient (originally 1.08), varies marginally between 1.04 and 1.09 , again with the exception of GIA, which gives 1.70 for $50 \%$ GIA and 0.72 for $150 \%$ GIA. If the $1 \sigma$ uncertainties of each contribution are used instead of simple scaling, the differences in regional $R^{2}$ vary between 0.82 and 0.89 , and the regression coefficients between 1.05 and 1.08 , again with the exception of GIA, which gives 1.29 for GIA- $1 \sigma$ and 0.89 for GIA $+1 \sigma$. This shows that, although small improvements may be made in some regions, in other regions the agreement decreases when one contribution at a time is changed. None of the options gives a structural improvement for all regions, and only varying GIA showed significant influence on the results. This shows that it is very important to have a good GIA estimate, while for all other contributions the response to scaling is minimal and thus the magnitude less critical.

We therefore test how the results change when we replace the GIA contribution of Peltier (2004) by the GIA model of Lambeck (ANU model Nakada and Lambeck, 1988, updated in 2004-2005). We find that this improves the results in 5 regions, but it decreases the match in the other regions. The $R^{2}$ is 0.80 and the regression coefficient 0.95 , which is a lower $R^{2}$ and similar regression coefficient as before. We therefore decided to use the Peltier (2004) GIA as the standard data set in this study.

Instead of varying the contributions one at a time, we can also allow all contributions to change at the same time, and minimise the error for all tide gauge locations. Using simple linear regression, we find

$$
\begin{aligned}
\text { Obs } & =(0.01 \times \text { steric })+(1.10 \times \text { ice sheets })+(2.24 \times \text { GIC }) \\
& +(0.89 \times \text { GIA })+(0.71 \times \text { AL })+(-0.58 \times \text { terr }) .
\end{aligned}
$$

For some contributions the optimised scaling seems physically reasonable, such as for ice sheets and GIA. However, others are required to scale far outside their error bounds or even switch sign, such as the terrestrial contribution. 
Since there is a difference between the global mean of the observations $\left(1.8 \mathrm{~mm} \mathrm{yr}^{-1}\right)$ and the contributions $\left(1.3 \mathrm{~mm} \mathrm{yr}^{-1}\right)$, the option for a spatial field with a constant value was included in the optimisation, which results in the following:

$$
\begin{aligned}
\text { Obs } & =(-0.09 \times \text { steric })+(0.54 \times \text { icesheets })+(1.89 \times \text { GIC }) \\
& +(0.90 \times \text { GIA })+(1.15 \times \text { AL })+(-0.48 \times \text { terr })+0.58 .
\end{aligned}
$$

In this case, the scaling in GIA and AL seems physically possible, while the other values again suggest changes far outside the error bounds or a reverse of the signal. The constant of $0.58 \mathrm{~mm} \mathrm{yr}^{-1}$ suggests that the entire field should be increased by this value, which is about the initial difference in the global mean. This all shows that while it is mathematically possible to minimise the error, this does not give physically meaningful results. These tests indicate that changes in magnitude of the contributions are not the sole solution to better closure, but that changes in the regional patterns or the addition of other, more local, contributions are needed to further improve and constrain the results.

One of the shortcomings is the estimate of the vertical displacement, which includes more than just GIA, such as for instance land subsidence. In a recent publication, Wöppelmann et al. (2014) used observations from the global positioning system (GPS) to correct TG measurements for vertical movements. Of their 76 TG stations, 51 overlap with the TGs used in this study. Although the data presented by Wöppelmann et al. (2014) cover a different period, we extracted the GPS correction from their supplementary data under the assumption that the GPS signal is stationary over the period studied (as is assumed in Wöppelmann et al., 2014). We compared the 51 GPS-corrected TG stations to the models minus the GIA component (which is already included in the GPS correction), versus the same 51 uncorrected TG stations compared to the full model set. We find that the GPS correction gives similar or better results in 11 of the 13 regions covered by the 51 TG stations. This means that if GPS corrections were available for a larger set of TGs, it would be beneficial for the amount of explained variability in our TG set and worthwhile to include in the analysis. It also implies that the explained variability can be improved by including more local processes rather than large-scale climate-driven processes.

\subsection{Global mean budget closure}

While this paper focuses on regional sea-level change, we here discuss the closure of the global mean sea-level budget. In Church et al. (2011) (henceforth C11), the different contributions and the observed global mean sea-level change were found to agree within $0.05 \mathrm{~mm} \mathrm{yr}^{-1}$ for the period 1972 2008, while for the contributions used in this study there is a difference of $0.51 \mathrm{~mm} \mathrm{yr}^{-1}$ (Table 2).

The contribution for AIS in this study is smaller than in $\mathrm{C} 11$, but $\mathrm{C} 11$ states that the AIS contribution can vary be- tween 0 and $0.4 \mathrm{~mm} \mathrm{yr}^{-1}$. For GIS, there is only a very small difference. The difference seems larger for the GIC, but since the trend in the Cogley (2009b) data used in C11 for the period 1961-2003 is lower than for 1972-2008, the difference is only $0.05 \mathrm{~mm} \mathrm{yr}^{-1}$.

For the steric contribution, Domingues et al. (2008) data are used for the upper $700 \mathrm{~m}$, while we use Levitus et al. (2012) for the upper $2000 \mathrm{~m}$. This results in a difference of $0.18 \mathrm{~mm} \mathrm{yr}^{-1}$ for the steric component. However, the data from Domingues et al. (2008) give a $0.15 \mathrm{~mm} \mathrm{yr}^{-1}$ lower estimate for the period 1961-2003 than for the C11 period. Hence the difference is again mainly caused by the different time periods considered.

For the terrestrial exchange component, $\mathrm{C} 11$ use the same data for the water impoundment behind dams, but due to the difference in period their contribution is less negative than the value used in this study as a result of larger groundwater extraction and fewer dams being constructed in more recent periods. In addition, $\mathrm{C} 11$ uses the lower estimates from Konikow (2011) for the groundwater extraction component, and adds a third component to the terrestrial exchange, termed natural terrestrial storage, both of which could not be included in this study because the spatial data was not available.

Overall, the difference between the budget closure in $\mathrm{C} 11$ and this study can be explained mainly by the difference in time period. While the contributions indicate larger trends for the later period, the TG-observed change is very similar, leading to a discrepancy over the 1961-2003 period. However, the availability of regional data limits the current analysis to the period up to 2003.

\section{Summary and conclusions}

This study compared TG-observed sea-level trends to regional sea-level patterns of different contributions for the period 1961-2003 to see how much of the measurements could be explained. The following contributions are included: land ice, steric, GIA, terrestrial water storage and atmospheric loading.

When comparing the individual observations to the net contributions (Sect. 3.2), we found that some of the observations could be explained rather well, while others showed large differences from the net contributions. Key processes in the explanation are the steric contribution, because of its high spatial variability, and the GIA, which can have a large regional influence. The regional means (Sect. 3.3) showed a better match of TG and net contributions in the regions than for the individual values, with high values for $R^{2}$ and a regression coefficient close to 1 . Moreover, the observations and models overlap within a $1 \sigma$ uncertainty range in all regions. The reason for the improvement is probably that by averaging over the regions, the extreme values of local measurements become less important. 
A comparison of probability distributions showed that the variability in the TG observations is slightly larger than in the net contributions. This can point to either too little variability in the contributions included, a missing contributing process, or may be inherent to the observations, which measure highly localised changes and might thus include non-climate related changes such as harbour works, local sedimentary processes or local tectonics.

The influence of variations on the estimates of the contributions, and how this might improve the explained variability in some regions, was discussed in Sect. 4.1. It appeared that changing the contributions one at a time, either by scaling or by using the $1 \sigma$ uncertainties, leads to marginal changes and none of them improved the results in all regions at the same time. Only scaling the GIA contribution leads to significant changes, but it does not give any improvements, nor does replacing the GIA by another estimate. When optimising for all contributions simultaneously, the results were not physically meaningful and required scaling the contributions far out of their respective uncertainty ranges. From this we can conclude that improvements need not necessarily be expected from changing the magnitude of the included contributions, but rather from spatial changes in the patterns of the regional distributions.

It can be concluded that the understanding of the processes seems to be relatively good at a larger, regionally averaged scale. The inclusion of the GIA contribution plays a large role in explaining the measurements. However, there is still a long way to go in the explanation of individual TG measurements. This includes not only improving the regional distributions of each of the modelled contributions, but possibly also adding other, more localised processes such as wind effects, changes in sediment transport or subsidence. A useful addition on the measurement side would be to equip each TG station with GPS measurements to correct for vertical and horizontal movements of the earth, which is being done at some TG stations now.

Acknowledgements. We would like to thank the NODC, PSMSL, J. Lenaerts, P. Stocchi, and B. Chao for the use of their data, and R. Riva for the updated sea-level model. We are grateful to D. Monselesan for his help on the steric analysis, and to N. White and S. Dangendorf for providing their tide gauge sets. NCEP Reanalysis Derived data were provided by the NOAA/OAR/ESRL PSD, Boulder, Colorado, USA, from their website at http://www.esrl.noaa.gov/psd/.

Edited by: A. Levermann

\section{References}

Antonov, J. I., Levitus, S., and Boyer, T. P.: Thermosteric sea level rise, 1955-2003, Geophys. Res. Lett., 32, L12602, doi:10.1029/2005GL023112, 2005.

Baart, F., van Gelder, P. H. A. J. M., de Ronde, J., van Koningsveld, M., and Wouters, B.: The Effect of the 18.6-Year Lunar Nodal Cycle on Regional Sea-Level Rise Estimates, J. Coast. Res., 28, 511-516, doi:10.2112/JCOASTRES-D-11-00169.1, 2012.

Bindoff, N. L., Willebrand, J., Artale, V., Cazenave, A., Gregory, J., Gulev, S., Hanawa, K., Quéré, C. L., Levitus, S., Nojiri, Y., Shum, C. K., Talley, L. D., and Unnikrishnan, A.: Observations: Oceanic Climate Change and Sea Level, in: Climate Change 2007: The Physical Science Basis. Contribution of Working Group I to the Fourth Assessment Report of the Intergovernmental Panel on Climate Change, edited by: Solomon, S., Qin, D., Manning, M., Chen, Z., Marquis, M., Averyt, K. B., Tignor, M., and Miller, H. L., Cambridge University Press, Cambridge, UK and New York, NY, USA, 2007.

Chao, B. F., Wu, Y. H., and Li, Y. S.: Impact of Artificial Reservoir Water Impoundment on Global Sea Level, Science, 320, 212214, doi:10.1126/science.1154580, 2008.

Church, J. A. and White, N. J.: Sea-Level Rise from the Late 19th to the Early 21st Century, Surv. Geophys., 32, 585-602, doi:10.1007/s10712-011-9119-1, 2011.

Church, J. A., White, N. J., Coleman, R., Lambeck, K., and Mitrovica, J. X.: Estimates of the regional distribution of Sea Level Rise over the 1950-2000 Period, J. Climate, 17, 2609-2625, 2004.

Church, J. A., White, N. J., Konikow, L. F., Domingues, C. M., Cogley, J. G., Rignot, E., Gregory, J. M., van den Broeke, M. R., Monaghan, A. J., and Velicogna, I.: Revisiting the Earth's sealevel and energy budgets from 1961 to 2008, Geophys. Res. Lett., 38, L18601, doi:10.1029/2011GL048794, 2011.

Cogley, J. G.: A more complete version of the World Glacier Inventory, Ann. Glaciol., 50, 32-38, 2009a.

Cogley, J. G.: Geodetic and direct mass-balance measurements: comparison and joint analysis, Ann. Glaciol., 50, 96-100, 2009b.

Dangendorf, S., Wahl, T., Nilson, E., Klein, B., and Jensen, J.: A new atmospheric proxy for sea level variability in the southeastern North Sea: observations and future ensemble projections, Clim. Dynam., doi:10.1007/s00382-013-1932-4, in press, 2013.

Domingues, C. M., Church, J. A., White, N. J., Gleckler, P. J., Wijffels, S. E., Barker, P. M., and Dunn, J. R.: Improved estimates of upper-ocean warming and multi-decadal sea-level rise, Nature, 453, 1090-1094, doi:10.1038/nature07080, 2008.

Dyurgerov, M. B. and Meier, M. F.: Glaciers and the Changing Earth System: A 2004 Snapshot, Tech. rep., Inst. of Arct. and Alp. Res., University of Colorado, Boulder, occas Pap No. 58, 2005.

Dziewonski, A. M. and Anderson, D. L.: Preliminary reference Earth model, Phys. Earth Planet Inter., 25, 297-356, 1981.

Ettema, J., van den Broeke, M. R., van Meijgaard, E., van de Berg, W. J., Bamber, J. L., Box, J. E., and Bales, R. C.: Higher surface mass balance of the Greenland ice sheet revealed by highresolution climate modeling, Geophys. Res. Lett., 36, L12501, doi:10.1029/2009GL038110, 2009.

Farrell, W. E. and Clark, J. A.: On Postglacial Sea Level, Geophys. J. R. Astron. Soc., 46, 647-667, 1976. 
Fiedler, J. W. and Conrad C. P.: Spatial variability of sea level rise due to water impoundment behind dams, Geophys. Res. Lett., 37, L12603, doi:10.1029/2010GL043462, 2010.

Gomis, D., Ruiz, S., Sotillo, M. G., Alvarez-Fanjul, E., and Terradas, J.: Low frequency Mediterranean sealevel variability: The contribution of atmospheric pressure and wind, Global Planet. Change, 63, 215-229, doi:10.1016/j.gloplacha.2008.06.005, 2008.

Gregory, J. M., White, N. J., Church, J. A., Bierkens, M. F. P., Box, J. E., van den Broeke, M. R., Cogley, J. G., Fettweis, X., Hanna, E., Huybrechts, P., Konikow, L. F., Leclercq, P. W., Marzeion, B., Oerlemans, J., Tamisiea, M. E., Wada, Y., Wake, L. M., and Van de Wal, R. S. W.: Twentieth-century global-mean sea-level rise: is the whole greater than the sum of the parts?, J. Climate, 26, 4476-4499, doi:10.1175/JCLI-D-12-00319.1, 2012.

Han, G., Ma, Z., Bao, H., and Slangen, A.: Regional differences of relative sea level changes in the Northwest Atlantic: Historical trends and future projections, J. Geophys. Res. Oceans, 119, 156-164, doi:10.1002/2013JC009454, 2014.

Holgate, S. J., Matthews, A., Woodworth, P. L., Rickards, L. J., Tamisiea, M. E., Bradshaw, E., Foden, P. R., Gordon, K. M., Jevrejeva, S., and Pugh, J.: New data systems and products at the Permanent Service for Mean Sea Level, J. Coast. Res., 29, 493-504, 2013.

Holzer, T. L. and Johnson, A. I.: Land Subsidence Caused by Ground Water Withdrawal in Urban Areas, GeoJ., 11, 245-255, doi:10.1007/BF00186338, 1985.

Ishii, M. and Kimoto, M.: Reevaluation of Historical Ocean Heat Content Variations with Time-Variying XBT and MBT Depth Bias Corrections, J. Oceanogr., 65, 287-299, 2009.

Kalnay, E., Kanamitsu, M., Kistler, R., Collins, W., Deaven, D., Gandin, L., Iredell, M., Saha, S., White, G., Woollen, J., Zhu, Y., Leetmaa, A., and Reynolds, R.: The NCEP/NCAR 40-year reanalysis project, Bull. Am. Meteorol. Soc., 77, 437-470, 1996.

Konikow, L. F.: Contribution of global groundwater depletion since 1900 to sea-level rise, Geophys. Res. Lett., 38, L17401, doi:10.1029/2011GL048604, 2011.

Landerer, F. W., Jungclaus, J. H., and Marotzke, J.: Ocean bottom pressure changes lead to a decreasing length-of-day in a warming climate, Geophys. Res. Lett., 34, L06307, doi:10.1029/2006GL029106, 2007.

Lenaerts, J. T. M., van den Broeke, M. R., van de Berg, W. J., van Meijgaard, E., and Munneke, P. K.: A new, high resolution surface mass balance map of Antarctica (1979-2010) based on regional climate modeling, Geophys. Res. Lett., 39, L04501, doi:10.1029/2011GL050713, 2012.

Levitus, S., Antonov, J., and Boyer, T.: Warming of the World Ocean, 1955-2003, Geophys. Res. Lett., 32, L02604, doi:10.1029/2004GL021592, 2005.

Levitus, S., Antonov, J. I., Boyer, T. P., Baranova, O. K., Garcia, H. E., Locarnini, R. A., Mishonov, A. V., Reagan, J. R., Seidov, D., Yarosh, E. S., and Zweng, M. M.: World ocean heat content and thermosteric sea level change (0-2000 m), 1955-2010, Geophys. Res. Lett., 39, L10603, doi:10.1029/2012GL051106, 2012.

Lombard, A., Garric, G., and Penduff, T.: Regional patterns of observed sea level change: insights from a $1 / 4^{\circ}$ global ocean/sea-ice hindcast, Ocean Dynam., 59, 433-449, doi:10.1007/s10236-0080161-6, 2009.
Mitrovica, J. X. and Peltier, W. R.: On Postglacial Geoid Subsidence Over the Equatorial Oceans, J. Geophys. Res., 96, 20053-20071, 1991.

Mitrovica, J. X., Tamisiea, M. E., Davis, J. L., and Milne, G. A.: Recent mass balance of polar ice sheets inferred from patterns of global sea-level change, Nature, 409, 1026-1029, 2001.

Nakada, M. Lambeck, K: The melting history of the late Pleistocene Antarctic ice sheet, Nature, 333, 36-40, 1988.

Nicholls, R. J. and Cazenave, A.: Sea-Level Rise and Its Impact on Coastal Zones, Science, 328, 1517-1520, doi:10.1126/science.1185782, 2010.

Peltier, W.: Global Glacial Isostasy and the Surface of the Ice-Age Earth: The ICE-5G (VM2) Model and GRACE, Annu. Rev. Earth Planet. Sci., 32, 111-149, 2004.

Pirazzoli, P. A.: A review of possible eustatic, isostatic and tectonic contributions in eight late-Holocene relative sea-level histories from the Mediterranean area, Quartenary Sci. Rev., 24, 19892001, doi:10.1016/j.quascirev.2004.06.026, 2005.

Plag, H.-P.: Recent relative sea-level trends: an attempt to quantify the forcing factors, Phil. Trans. R. Soc. A, 364, 821-844, doi:10.1098/rsta.2006.1739, 2006.

Purkey, S. G. and Johnson, G. C.: Warming of Global Abyssal and Deep Southern Ocean Waters between the 1990s and 2000s: Contributions to Global Heat and Sea Level Rise Budgets, J. Climate, 23, 6336-6351, doi:10.1175/2010JCLI3682.1, 2010.

Rhein, M., Rintoul, S. R., Aoki, S., Campos, E., Chambers, D., Feely, R. A., Gulev, S., Johnson, G. C., Josey, S. A., Kostianoy, A., Mauritzen, C., Roemmich, D., Talley, L. D, and Wang, F.: Observations: Ocean, in Climate Change 2013: The Physical Science Basis. Contribution of Working Group I to the Fifth Assessment Report of the Intergovernmental Panel on Climate Change, edited by: Stocker, T. F., Qin, D., Plattner, G.-K., Tignor, M., Allen, S. K., Boschung, J., Nauels, A., Xia, Y., Bex, V., and Midgley, P. M., Cambridge University Press, Cambridge, United Kingdom and New York, NY, USA, 2013.

Rignot, E., Velicogna, I., van den Broeke, M. R., Monaghan, A., and Lenaerts, J.: Acceleration of the contribution of the Greenland and Antarctic ice sheets to sea level rise, Geophys. Res. Lett., 38, L05503, doi:10.1029/2011GL046583, 2011.

Ross, J. C.: On the effect of the pressure of the atmosphere on the mean level of the ocean, Phil. Trans. R. Soc., 144, 285-296, 1854.

Schotman, H. H. A. and Vermeersen, L. L. A.: Sensitivity of glacial isostatic adjustment models with shallow low-viscosity earth layers to the ice-load history in relation to the performance of GOCE and GRACE, Earth Planet. Sci. Lett., 236, 828-844, 2005.

Slangen, A. B. A., Katsman, C. A., van de Wal, R. S. W., Vermeersen, L. L. A., and Riva, R. E. M.: Towards regional projections of twenty-first century sea-level change based on IPCC SRES scenarios, Clim. Dynam., 38, 1191-1209, doi:10.1007/s00382-011-1057-6, 2012.

Slangen, A. B. A., Carson, M., Katsman, C., van de Wal, R., Koehl, A., Vermeersen, L., and Stammer, D.: Projecting twenty-first century regional sea-level changes, Clim. Change, 124, 317-332, doi:10.1007/s10584-014-1080-9, 2014. 
Tsimplis, M., Spada, G., Marcos, M., and Flemming, N.: Multidecadal sealevel trends and land movements in the MediterraneanSea with estimates of factors perturbing tide gauge data and cumulative uncertainties, Global Planet. Change, 76, 63-76, doi:10.1016/j.gloplacha.2010.12.002, 2011.

Wada, Y., van Beek, L. P. H., Weiland, F. C. S., Chao, B. F., Wu, Y.H., and Bierkens, M. F. P.: Past and future contribution of global groundwater depletion to sea-level rise, Geophys. Res. Lett., 39, L09402, doi:10.1029/2012GL051230, 2012.

Wöppelmann, G., Marcos, M., Santamaría-Gómez, A., MartínMíguez, B., Bouin, M., and Gravelle, M.: Evidence for a differential sea level rise between hemispheres over the twentieth century, Geophys. Res. Lett., 41, 1639-1643, doi:10.1002/2013GL059039, 2014.
Woodward, R. S.: On the Form and Position of the Sea-level as Dependent on Superficial Masses Symmetrically Disposed with Respect to a Radius of the Earth's Surface, Ann. Mathem., 3, 11-26, 1887.

Wunsch, C. and Stammer, D.: Atmospheric loading and the oceanic "inverted barometer" effect, Rev. Geophys., 35, 79-107, 1997.

Wunsch, C., Ponte R. M., and Heimbach P.: Decadal trends in sea level patterns: 1993-2004 J. Climate, 20, 5889-5911, doi:10.1175/2007JCLI1840.1 